\title{
ТЕХНОЛОГИЧЕСКОЕ ПРЕДПРИНИМАТЕЛЬСТВО В РОССИИ
}

\author{
(C) 2021 Удальцова Н.Л. \\ кандидат экономических наук, доцент департамента Менеджмента и инноваций \\ Высшая школа управления \\ Финансовый университет при Правительстве Российской Федерации, Россия, Москва \\ E-mail: Udaltsova.nl@yandex.ru
}

Научная статья посвящена исследовательскому анализу особенностей современного развития инновационного и технологического предпринимательства в России. Актуальность исследования обусловлена тем, что в рамках цифровой трансформации российской и международной экономики все большее число предпринимательских субъектов формируют бизнес-направления технологического производства и разработки инновационных проектов, направленных на создание уникальных продуктов, инноваций и информационных технологий. В рамках статьи проанализированы тенденции развития технологического предпринимательства и инновационной деятельности в экономике России. Описаны наиболее приоритетные направления бизнес-деятельности технологических и инновационно-ориентированных предприятий. Проанализированы наиболее известные инновационные компании и их продукты. Описаны особенности функционирования малого инновационного бизнеса в России. Проанализированы актуальные проблемы крупных и малых предприятий, функционирующих в секторе информационных технологий (IT-сфере). Описаны особенности и барьеры при финансировании технологического и инновационного предпринимательства в России.

Ключевые слова: технологическое предпринимательство; инновационное предпринимательство; инновационная деятельность; инновационные технологии; инновационные проекты; стартаппроекты; инновации; цифровая экономика; циифровая трансформация; инновационная активность; производство информационных технологий.

На сегодняшний день технологическое предпринимательство выступает одним из ключевых компонентов развития конкурентоспособности национальной экономики каждого государства, в том числе и Российской Федерации.

Одним из главных факторов развития технологического предпринимательства выступает четвертая промышленная революция, сформированная при переходе с пятого на шестой технологический уклад. При этом, развитие технологий привело не только к процессам разработки и производства технологий, но и к активному процессу международного обмена интеллектуальной собственностью, в частности путем экспорта и импорта инноваций, патентов, лицензий, оборудования и других объектов интеллектуального капитала.

Стоит отметить, что шестой технологический уклад начался в 2010-х гг. и связан был с практическим применением таких инноваций как цифровые технологий, особенностью которых выступала цифровизация.

Если предыдущая (третья) промышленная революция была нацелена на автоматизацию производственных процессов, что мы наблюдали в рамках модернизации промышленных объектов и предприятий российской и зарубежной экономики, то четвертая промышленная революция ставит задачей процесс цифровизации всех бизнес-процессов и операционных систем, связанных с производством продукции и управлением предприятием [1].

На фоне развития шестого технологического уклада и четвертой промышленной революции технологическое предпринимательство выступает неотъемлемым составляющим современного этапа развития национальной экономики России и ее инновационной системы.

Актуальность исследования обусловлена тем, что в рамках цифровой трансформации российской и международной экономики все большее число предпринимательских субъектов формируют бизнес-направления технологического производства и разработки инновационных проектов, направленных на создание уникальных продуктов, инноваций и информационных технологий.

$\mathrm{K}$ основам инновационной экономики 
стоит относить отрасли и предприятия, производственная деятельность которых заострена на разработку и производство инновационной продукции, где в рамках самого производства используются инновационные технологии, а капитальные инвестиции финансовых ресурсов направленны, в основном, на научно-исследовательские и конструкторские работы.

Так, на рисунке 1 изображена динамика патентной активности предприятий в экономике России.

В период с 2015 по 2019 год число действующих патентов увеличилось с 292 тысяч до 341,6 тысяч. При этом ежегодная выдача патентов на изобретения ускорилась с 33950 в 2015 году до 35774 в 2019 году.

Однако наиболее важным элементом инновационной экономики Российской Федерации является формирование национальной инновационной системы.

Под национальной инновационной системой (НИС) подразумевается совокупность государственных и частных институтов, взаимодействие между которыми позволяет формировать и распространять новые знания, технологии и инновации [2].

Структура НИС государства состоит из следующих подсистем:

- рынок наукоемкой продукции и услуг;

- генерация знаний и объектов интеллектуальной собственности;

- производство инноваций;
- инновационная инфраструктура;

- система образования и профессиональной подготовки.

Задачей развития инновационной экономики в России является обеспечение условий, при которых будет увеличиваться объем производства наукоемкой продукции, доля которой крайне низка.

Одними из основных проблем развития инновационной экономики и технологического предпринимательства в России выступают следующие факторы [3; 4]:

- дефицит бюджетных средств и недостаточный уровень финансирования национальных и региональных проектов, обеспечивающих формирование инновационной активности в экономике страны;

- проблемы обеспечения защиты объектов интеллектуальной собственности в России;

- барьеры при доступе инновационных организаций к внешним источникам финансирования, в особенности, когда речь идет об привлечении заемных средств;

- низкий уровень инновационной активности отечественных предприятий;

- отток человеческих ресурсов и талантливых сотрудников из России в зарубежные страны, из-за чего инновационно-ориентированные предприятия сталкиваются с дефицитом квалифицированных кадров;

- слабый уровень развития субъектов малого и среднего бизнеса, которые выступают основными участниками национальной инно-

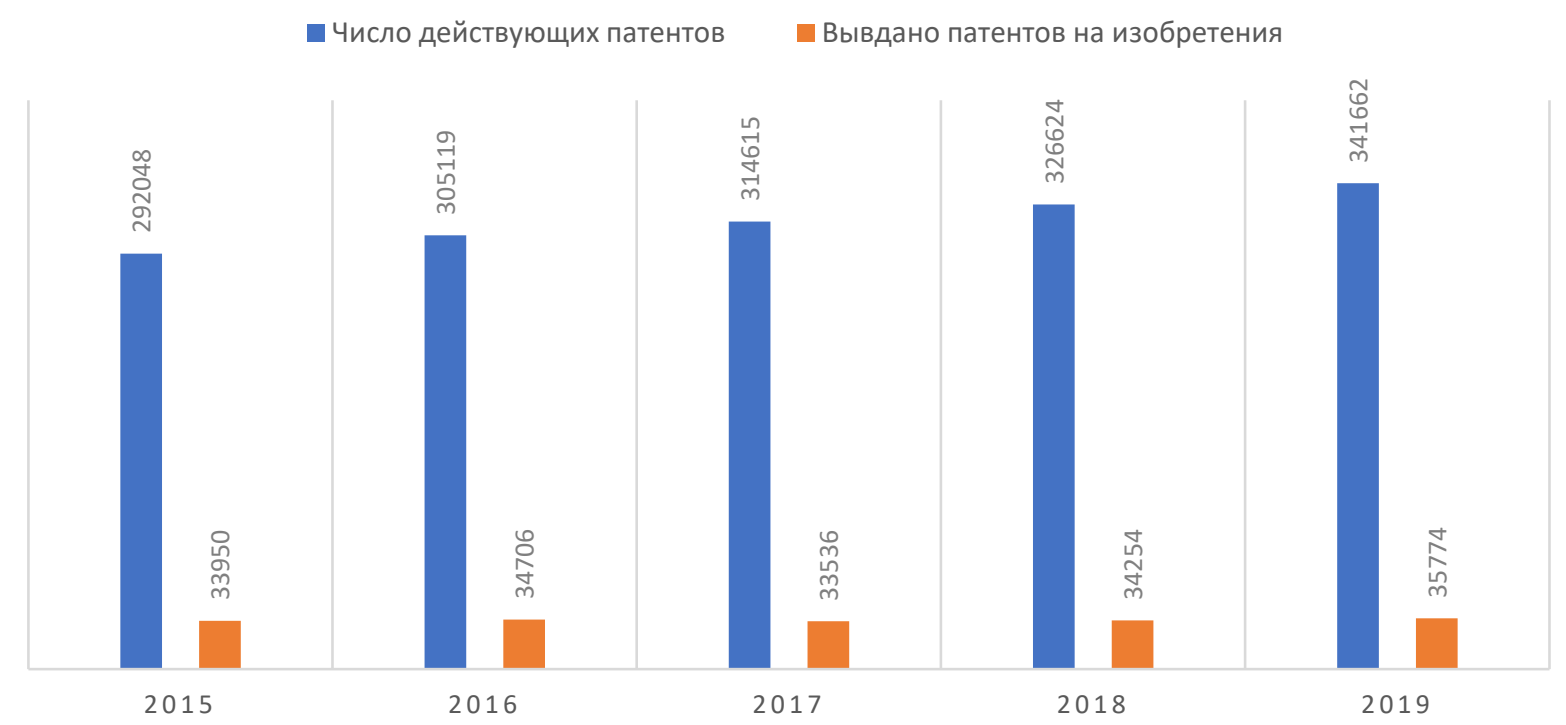

Рисунок 1. Патентная активность в Российской Федерации [11]. 
вационной системы в зарубежных странах, занимающих лидирующие позиции в глобальном индексе развития инноваций.

Также к проблеме развития технологического предпринимательства в России относится сокращение численности персонала, занятого в научно-исследовательских и конструкторских работах (см. рисунок 2).

Однако, несмотря на данные проблемы, главной особенностью инновационного развития национальной экономики Российской Федерации является применение информационных и цифровых технологий, которые совершенствуют управление бизнес-процессами предприятий.

Основными направлениями бизнесдеятельности технологических предприятий выступают:

- аутсорсинг бизнес-процессом IT-сферы;

- предоставление услуг в виде цифровых сервисов и онлайн-приложений;

- проведение разработки и ведение проектов других компаний;

- предоставление сервисной поддержки информационной системы других компаний;

- разработка технологий и информационных систем.

Анализируя основные направления инновационной деятельности технологического бизнеса в России стоит выделить следующие категории технологий, которые интересны современным компаниям:

1. Облачные технологии, к которым проявляют интерес не только крупные компании, но и малые фирмы, поскольку последние не имеют возможности сразу развернуть собственную структуру для обработки данных.

2. Применение технологий искусственного интеллекта и машинного обучения. Данные инновации позволяют использовать инструменты качественного распознавания информации для расширения цифровых возможностей при бухгалтерском, налоговом и управленческом учете.

3. Цифровые технологии маркетинговой деятельности. К ним относятся такие инструменты, как:

- SEO, благодаря которому проводится повышение трафика и увеличивается конверсия рекламных предложений;

- медийная реклама, которая позволяет сделать максимальный охват аудитории и повышает узнаваемость бренда и торговой марки;

- SMM, который способен для предприятий иметь минимальные затраты денежных средств на продвижение и приводит живую аудиторию;

- контент-маркетинг, который позволяет завоевать доверие потребителей, увеличить узнаваемость бренда и торговой марки, и имеет высокий уровень взаимодействия с SEO.

4. Технологии Big Data, которые позволяют обработать большой объем неструктурированных данных, систематизировать их, проанализировать и выявить закономерности там, где человеческий мозг никогда бы их не заметил [7].

Их первоначальное предназначение направлено на систематический анализ больших данных. Однако, в данный момент, технологии Big

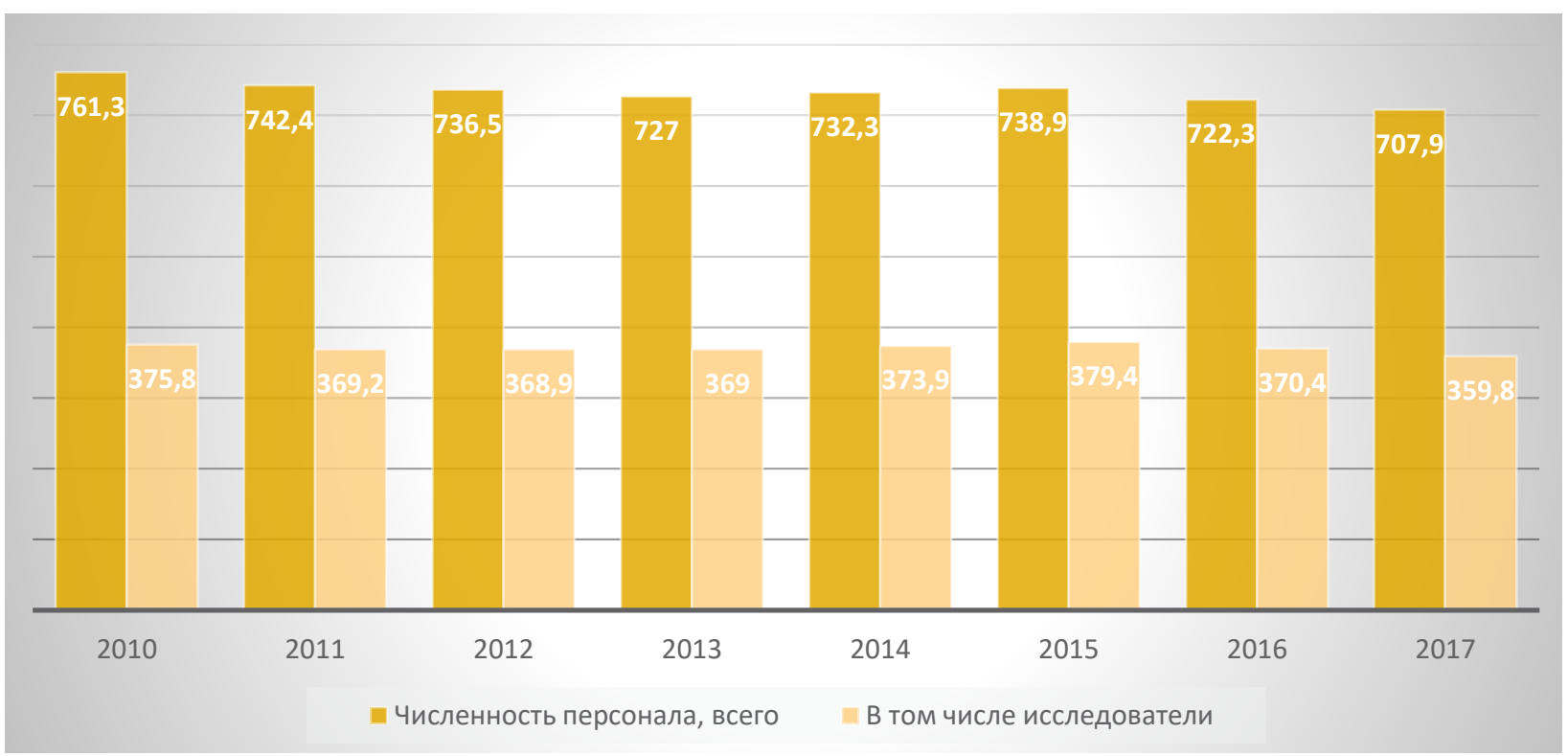

Рисунок 2. Динамика численности персонала, занятого в научных исследованиях, в тыс. человек [11]. 
Data крайне актуальны в рамках анализа и оценки рисков корпоративных финансов. Их применение используют такие крупные компании российской экономики, как «Сбербанк», «Роснефть», «Газпром» и другие.

Анализируя наиболее известные компании России, занимающиеся современными технологиями и инновациями, их можно разделить на 2 ключевые группы. В первую группу стоит отнести два банка - Сбербанк и Тинькофф, которые выступают одними из наиболее инновационных кредитных организаций в Европе. В таблице 1 проведен сравнительный анализ их продуктов и технологий.

Во вторую группу входят другие компании и IT-предприятия. Среди компаний IT-сферы наиболее известными выступают Яндекс и Майл.ру.

Главными технологическими продуктами компании Яндекс выступают:

- Яндекс.Поиск;

- Янлекс.Музыка;

- Кинопоиск;

- Яндекс.Карты;

- Auto.ru;

- Яндекс.Директ;

- Яндекс.Доставка.
Главными технологическими продуктами компании Майл.ру выступают:

- Мой мир;

- Вконтакте;

- Одноклассники;

- Delivery Club;

- Qiwi кошелек.

Также стоит отметить, что главным источником формирования инновационных технологий выступают стартапы, задачей которых является создание и производство продукции инновационного характера и для получения финансового результата (в виде прибыли).

Инновационная деятельность стартапов для экономики России стала ключевой основой формирования цифровизации национальной экономической системы, где возникает необходимость в инновационной инфраструктуре.

Однако, одними из острых вопросов и проблем функционирования стартапов в отечественной экономике выступает их финансирование, состоящее в основном из альтернативных источников, к которым относятся венчурное финансирование, краудфандинг, факторинг, краудинвестинг и т.д.

Поскольку стартапы - это молодые пред-

Таблица 1. Сравнительный анализ степени инновационной ориентации банковской деятельности «Тинькофф Банк» и «Сбербанк России».

\begin{tabular}{|c|c|c|}
\hline Критерий/показатель & «Тинькофф Банк» & «Сбербанк России» \\
\hline $\begin{array}{c}\text { Основные цифровые } \\
\text { продукты и услуги }\end{array}$ & $\begin{array}{c}\text { Лайфстайл-сервисы, позволяющие ку- } \\
\text { пить билеты, забронировать столики } \\
\text { и многое другое } \\
\text { Финансовый голосовой помощник } \\
\text { Stories в мобильном банкинге } \\
\text { Биометрия при идентификации кли- } \\
\text { ентов }\end{array}$ & $\begin{array}{c}\text { Сервис перевода цифровых валют } \\
\text { Ю-Мопеу } \\
\text { Сервис СберЗдоровье } \\
\text { Сервис аутсорсинга СберРешения }\end{array}$ \\
\hline $\begin{array}{c}\text { Востребованность предо- } \\
\text { ставляемых цифровых услуг } \\
\text { и продуктов }\end{array}$ & $\begin{array}{c}\text { Количество клиентов Тинькофф банка } \\
\text { и его цифровых продуктов являют- } \\
\text { ся 10,7 млн. человек, общий объем } \\
\text { средств которых составляет 302,2 } \\
\text { млрд. рублей }\end{array}$ & $\begin{array}{c}\text { Сбербанк Бизнес Онлайн в виде } \\
\text { веб-версии и мобильного приложения } \\
\text { сегодня пользуются более 2,2 млн. } \\
\text { компаний } \\
\text { Интернет-банком для частных кли- } \\
\text { ентов Сбербанк Онлайн пользуются } \\
\text { более } 60 \text { млн. человек }\end{array}$ \\
\hline $\begin{array}{c}\text { Методы предоставления } \\
\text { цифровых услуг и продуктов }\end{array}$ & $\begin{array}{c}\text { Тинькофф банк сосредоточен на про- } \\
\text { движение и реализацию своих цифро- } \\
\text { вых продуктов и услуг через онлайн- } \\
\text { пространство. Используется активная } \\
\text { маркетинговая стратегия в социаль- } \\
\text { ных сетях, обслуживание и открытие } \\
\text { счетов происходит через интернет- } \\
\text { банкинг и мобильный банкинг }\end{array}$ & $\begin{array}{c}\text { Сбербанк имеет в России } 88 \text { филиа- } \\
\text { лов и } 13152 \text { дополнительных офиса. } \\
\text { Такое широкое представительство } \\
\text { позволяет охватывать масс-маркет } \\
\text { и предлагать цифровые продукты } \\
\text { через банковские отделения. Актив- } \\
\text { ное продвижение цифровых услуг } \\
\text { происходит и через социальные сети } \\
\text { и интернет-среду. Из-за расчетно- } \\
\text { кассовых операций, 81\% россиян } \\
\text { пользуются услугами Сбербанка, что } \\
\text { позволяет через них проводить актив- } \\
\text { ное предоставление цифровых услуг и } \\
\text { продуктов }\end{array}$ \\
\hline
\end{tabular}


приятия, как правило, созданные начинающими предпринимателями, у которых нет истории и опыта, основные источники привлечения внешнего финансирования, такого как коммерческое кредитование от банков, становятся попросту недоступным [9].

Кредитные организации требуют большую базу финансовой документации, отчетности, которая подтверждает устойчивость бизнеса, его развития, масштабирования и платежеспособности. Оценка кредитоспособности стартапов на минимальном уровне, вследствие чего им необходимо искать альтернативные источники финансирования.

Поскольку современный этап развития экономической системы сопряжен с формированием цифровизации различных процессов, наблюдается улучшение ситуации с привлечением инвестиций и финансовых ресурсов со стороны стартапов. Те же краудфандинговые площадки продемонстрировали по итогам 2018 года рост своей рыночной капитализации на территории Российской Федерации практически в трехкратном размере в сравнении с 2017 годом.

Также, важным вопросом развития стартапов является их взаимодействие с крупными компаниями, которые, как правило, выступают главными инвесторами и потребителями инновационной продукции. Ключевыми форматами взаимодействия стартапов и крупных компаний в экономике России выступают [8]:

- прямое инвестирование, слияние и поглощение компаний;

- корпоративные акселераторы и инкубаторы;

- корпоративные венчурные фонды;

- хакатоны, конкурсы стартапов, питч-сессии, панельные дискуссии;

- совместные лаборатории, научноисследовательские кабинеты и центры инноваций.

Современная роль стартапов в рамках формирования инновационной деятельности отечественной экономики настолько высокая, что их бизнес влияет на процесс модернизации и совершенствования систем крупнейших компаний и коммерческих банков Российской Федерации.

Однако, современные условия функционирования стартапов экономики Российской Федерации ухудшаются, что связано с распространением пандемии коронавируса COVID-19, негативные воздействия которой повышают степень влияния различных экономических рисков на коммерческую деятельность предприятиЙ.

В виду наращивания таких рисков отечественные стартапы сталкиваются с осложнениями и дополнительными барьерами в обеспечении финансового механизма функционирования своей предпринимательской и инновационной деятельности.

Ключевыми направлениями и перспективами развития технологического предпринимательства в России могут выступать [5; 6]:

- мощный всплеск экономического роста и снижения материальных затрат при производстве продукции, удовлетворяющей потребности людей;

- появится новая форма занятости, рынок труда претерпит структурную революцию, в связи с чем появятся новые профессии и трудовые специальности;

- произойдет массовая автоматизация промышленного производства, где человеческий труд будет заменен компьютерными программами и роботами;

- усиление угрозы социально-экономического неравенства между различными категориями населения;

- рост производительности труда;

- повышение уровня качества жизни населения региона;

- обеспечение развития конкурентной политики, прозрачности конкурентных отношений и замедление темпов картелизации бизнеса.

Также на сегодняшний день происходит реализация государственной программы «Цифровая экономика Российской Федерации», которая играет важнейшую стратегическую роль в дальнейшем социально-экономическом развитии нашей страны.

На рисунке 3 отображена динамика показателя вклада цифровизации в экономический рост валового внутреннего продукта России за последние 10 лет.

Таким образом, в период 2018-2019 гг. при начале реализации первых мероприятий Правительства РФ, направленных на цифровизацию национальной экономической системы, можно отметить резкое увеличение вклада данного процесса в экономический рост страны и изменение объема ВВП.

С целью способствования положительного 
6

5

4

3

2

0
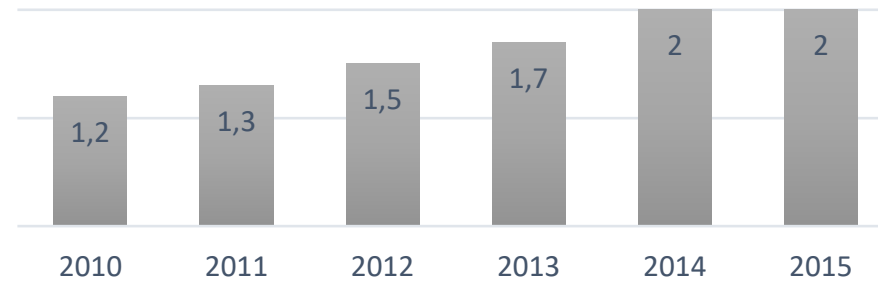

2014

2015
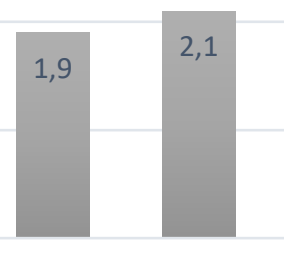

3,9

Рисунок 3. Динамика показателя вклада цифровизации в экономический рост ВВП России за период 2010-2019 гг., в\% [10].

воздействия технологического предпринимательства на динамику макроэкономических показателей, Правительству РФ необходимо формирование государственных программ финансовой поддержки инновационной активности и научно-исследовательской деятельности некоммерческих организаций (институтов и инновационных центров) и коммерческих структур (предприятий, венчурных фондов и бизнес- акселераторов).

Дальнейшие перспективы становления цифровой экономики и национальной инновационной системы в России достаточно позитивные, что позволяет сделать заключение о том, что данная модель трансформации национальной системы и рынков позволит простимулировать переход отечественных производителей на интенсивный путь к развитию.

\section{Библиографический список}

1. Щетинина Н. Ю. Индустрия 4.0: практические аспекты реализации в российских условиях // Модели, системы, сети в экономике, технике, природе и обществе. 2017. № 1 (21).

2. Модели формирования национальных инновационных систем. URL: http://kapital-rus.ru/articles/article/ modeli_formirovaniya_nacionalnyh_innovacionnyh_sistem/ (дата обращения: 26.04.2021).

3. Кешелава А.В. Цифровая трансформация предприятия. URL: http://spkurdyumov.ru/digital_economy/ cifrovaya-transformaciya-predpriyatiya/ (дата обращения: 26.04.2021).

4. Gorodnova N. V. The information technology industry in Russia: Current position and future prospects. In: 32nd International Business Information Management Association Conference, IBIMA 2018. International Business Information Management Association, IBIMA, 2018. p. 1221-1234.

5. Громов И. А. Влияние цифровых технологий на сферу государственных и бизнес-услуг в России // ПСЭ. 2018. № 3 (67).

6. Ивановский Б. Г. Социально-экономические последствия развития цифровых технологий // Социальные и гуманитарные науки: Отечественная и зарубежная литература. Сер. 2, Экономика: Реферативный журнал. 2018. № 4 .

7. Веретенников A. B. BigData: анализ больших данных // Молодой ученый. 2017. № 32 (166). C. 9-12.

8. Патлис В. Финансирование стартапа при его переходе в бизнес-единицу // Наука и инновации. 2017 . № 173.

9. Бондаренко Т.Г., ИсаеваЕ.А. Стартапы в России: актуальные вопросы развития // Вестник евразийской науки. 2015. № 5 (30).

10. Матвеев В.В., Тарасов В.А. Государственное регулирование и поддержка цифровой экономики в России // Инновационная экономика: перспективы развития и совершенствования. 2019. № 4 (38).

11. Наука и инновации. URL: https://rosstat.gov.ru/folder/14477 (дата обращения: 28.04.2021). 